\title{
Mendeléeff (I834-I907) and the Periodic Law
}

$\mathrm{D}$ MITRI IVANOWITSCH MENDELEEEFF, who was born on February 7, 1834 (N.S.) and was for many years professor of chemistry at Leningrad, is chiefly remembered for the first clear and satisfactory enunciation of the Periodic Law, the discovery having been made in the latter part of the year 1868 and announced in 1869 . $\mathrm{He}$ found that when the chemical elements are set out in an unbroken row in the order of the atomic weights, certain breaks become apparent, and the whole range divides itself into groups of related elements. This result, expressed in the law that "the properties of the elements are in periodic dependence on the atomic weights" is the basis of the Periodic System, or Periodic Table. In arriving at this conclusion, Mendeléeff was influenced mainly by the previous attempts at classification made by Dumas, Lenssen, Pettenkofer and Kremers, especially the first two, those of Newlands in 1863, and of others, being unknown to him. A similar result had been achieved by Lothar Meyer in 1868, but was not published.

A German abstract of Mendeléeff's discovery, containing all the essential features, appeared in 1869 , in which year it was thus generally known in Europe, and a long paper of 1871 gave a table which is essentially in its modern form. These publications attracted very little attention, but the interest of chemists was aroused by the discovery, in 1875 and 1879 , respectively, of the elements gallium and scandium, which were found to have the properties predicted for the missing elements which Mendeléeff had called ekaaluminium and ekaboron, places for them being reserved in the table. The element germanium, discovered in 1866, was also recognised as the ekasilicon of Mendeléeff. These discoveries made it clear that the Periodic Law was a fundamental truth, and the further progress of research has emphasised more and more its supreme importance in the study of the elements.

The discovery of argon was an indication to Ramsay that a new group of elements of zero valency must be added to the table, and the elements helium, neon, krypton and xenon were before long added to the group, and the last member is the radioactive emanation. The suggestions of Mendeléeff that this group also contained two other elements, one being the ether, of very small atomic weight, and the other an unknown element of atomic weight less than 0.4 , and that there was a missing element of the halogen group, of atomic weight 3 , have appeared inconsistent with modern views of the structure of the atomic nucleus.

The regularities among the atomic weights of the elements as disclosed in the Periodic System could not fail to revive speculations about a primary matter, which had attracted chemists since Prout had suggested that this primary matter was hydrogen. Mendeléeff was entirely opposed to this hypothesis of primary matter. The difficulty of fractional atomic weights was removed by the discovery that many elements are mixtures of isotopes, and the investigations on atomic structure showed that the Periodic Law is a consequence of the formation of atoms from protons and electrons. This recognition of isotopes also removed the objection that some pairs of elements, such as iodine and tellurium, were apparently placed in the wrong order in the table on the basis of their atomic weights, their true positions never being in doubt. The discovery that the position of an element in the table is really conditioned by its atomic number, or the positive charge on the atomic nucleus, gave the Periodic Law a fundamental character, and the theory of atomic disintegration enabled all the newly discovered radioactive elements to find their places in the lower part of the table, in many cases a single place containing several isotopes of the same atomic number.

An outstanding difficulty was the position of the elements of the rare earths. After lanthanum and cerium came a large number, not definitely known, of elements of very closely related properties, clearly belonging to the same group. After these came the element tantalum, obviously in the fifth group. For many years the rare earth element cerium, which forms very stable compounds in which it is quadrivalent, was considered to be the fourth group element of the rare earths. This difficulty was overcome on the basis of the theory of atomic structure by Bohr. The pronounced tervalent character of the rare earth elements, preserved with steadily increasing atomic weight, was shown to be a consequence of the presence in their atoms of incompleted inner electron levels, the filling up of which, by successive additions of electrons to keep step with the increasing nuclear charge, left unchanged the outer valency electrons. The atomic numbers of the rare earths were also determined by X-ray spectroscopy, and a knowledge of these, together with the information on the numbers of electrons in completed groups which resulted from general atomic theory, showed that an unknown element of the fourth group must come before tantalum. This element was shortly afterwards discovered in hafnium. There was also, it was clear, an earlier unknown element in the rare earth group, which has been found in illinium. The group of rare earths was then known to be complete.

The Periodic Law has thus assisted very materially in promoting discovery and has shown itself to be a truth of great extension and depth. Mendeléeff himself said: "I have never once doubted the universality of this law, because it could not possibly be the result of chance." It is, in fact, the great guiding principle in the study of the structure of the atom. 